\title{
CORRIGENDUM
}

\section{Cancer-related fatigue and depression in breast cancer patients postchemotherapy: Different associations with optimism and stress appraisals- CORRIGENDUM}

\author{
INBAR LEVKOVICH, MIRI COHEN, SHIMON POLLACK, KAREN DRUMEA, AND \\ GEORGETA FRIED
}

doi: http://dx.doi.org/10.1017/S147895151400087X, Published by Cambridge University Press, September 9, 2014.

The abstract of this article contained an error in the Results section.

In the abstract, lines 11-16 should read as follows:

\begin{abstract}
Results: We found levels of depression, CRF, and appraisals of cancer as a threat to be moderate and levels of optimism and appraisals of cancer as a challenge to be high. Depression and CRF were positively associated. A multivariate regression analysis revealed that $51 \%$ of the $\mathrm{CRF}$ variance was explained; physical symptoms and threat appraisal were significantly associated with CRF. A 67\% of the CRF variance of depression was explained; challenge and threat appraisals were significantly associated with depression.
\end{abstract}

The author regrets this error.

\section{REFERENCE}

Levkovich, I., Cohen, M., Pollack, S., et al. (2015). Cancer-related fatigue and depression in breast cancer patients postchemotherapy: Different associations with optimism and stress appraisals. Palliative and Supportive Care, 13(5), 1141-1151. doi:10.1017/S147895151400087X. 